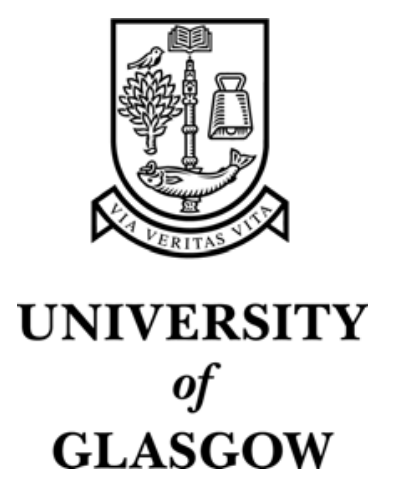

Singh, C. and Peake, D.J. and Kokkalis, A. and Khodagolian, V. and Coton, F.N. and Galbraith, R.A.McD. (2006) Control of rotorcraft retreating blade stall using air-jet vortex generators. Journal of Aircraft 43(4):pp. 1169-1176.

http://eprints.gla.ac.uk/3384/ 


\title{
Control of Rotorcraft Retreating Blade Stall Using Air-Jet
}

\section{Vortex Generators}

\author{
Chrisminder Singh ", David J. Peake ${ }^{\dagger}$, Anastassios Kokkalis ${ }^{\ddagger}$, Vahik Khodagolian ${ }^{\S}$ \\ Centre for Aeronautics, City University, London, ECIV OHB, UK \\ Frank N. Coton ${ }^{\text {II }}$ and Roderick A. M' D. Galbraith ${ }^{\#}$ \\ Department of Aerospace Engineering, University of Glasgow, Glasgow, G128QQ, UK
}

\begin{abstract}
A series of low-speed wind tunnel tests were carried out on an oscillating airfoil fitted with two rows of air-jet vortex generators (AJVGs). The airfoil used had an RAE 9645 section and the two spanwise arrays of AJVGs were located at $\mathrm{x} / \mathrm{c}=\mathbf{0 . 1 2}$ and 0.62 . The devices and their distribution were chosen to assess their ability to modify/control dynamic stall; the goal being to enhance the aerodynamic performance of helicopter rotors on the retreating blade side of the disc. The model was pitched about the quarter chord with a reduced frequency (k) of 0.1 in a sinusoidal motion defined by $a=15^{\circ}+10^{\circ} \sin \omega t$. The measured data indicate that, for continuous blowing from the front row of AJVGs with a momentum blowing coefficient $\left(\mathrm{C}_{\mu}\right)$ greater than 0.008 , modifications to the stalling process are encouraging. In particular, the pitching moment behavior exhibits delayed stall and there is a marked reduction in the normal force hysteresis.
\end{abstract}

\footnotetext{
${ }^{*}$ Research Assistant, Centre for Aeronautics

† (Formerly) Professor, Centre for Aeronautics, (Currently) Vice President of Research \& Program Development, National Institute of Aerospace, Hampton, VA. Associate Fellow AIAA

* Professor, Centre for Aeronautics, Senior Member AIAA

${ }^{\S}$ Research Assistant, Centre for Aeronautics

II Professor of Low Speed Aerodynamics, Department of Aerospace Engineering, Member AIAA

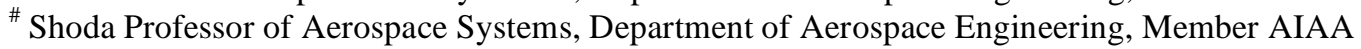




\section{Nomenclature}

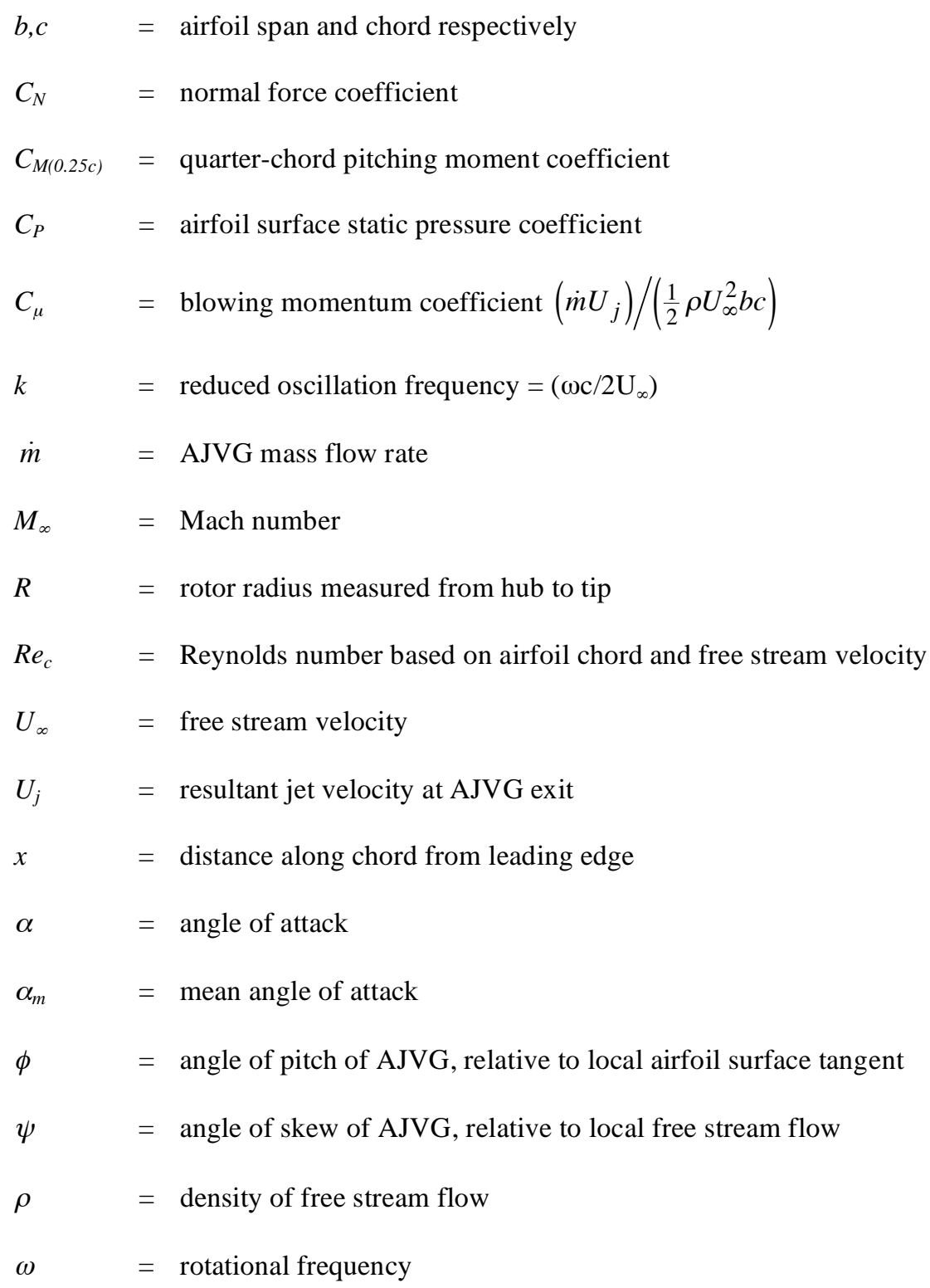

\section{Introduction}

During the forward flight of a helicopter (as depicted in Fig. 1), the combination of the forward and the rotational speeds results in large variations of local velocities over the rotor blades as they rotate. The effect, generally leads to the categorization of the rotor disc into an advancing side, where the local velocities are increased, and a retreating side where they are decreased. If nothing were done to the rotor, these variations in speed would result in 
an imbalance or out-of-trim rotor. The trimming of the rotor disk is simply done by the application of cyclic pitch. Hence, when the local speed is low, the rotor blade is pitched up and vice-versa. With increasing forward speed, and hence advance ratio, the required cyclic pitch becomes so severe that the rotor blade can experience stall. This dynamic stalling is one of the factors that limit the aircraft's maximum forward speed.

In general, dynamic stall is to be avoided. It can be characterized by the formation, migration and shedding of a leading-edge vortex (LEV) or dynamic stall vortex (DSV). The movement of this vortical structure across the airfoil

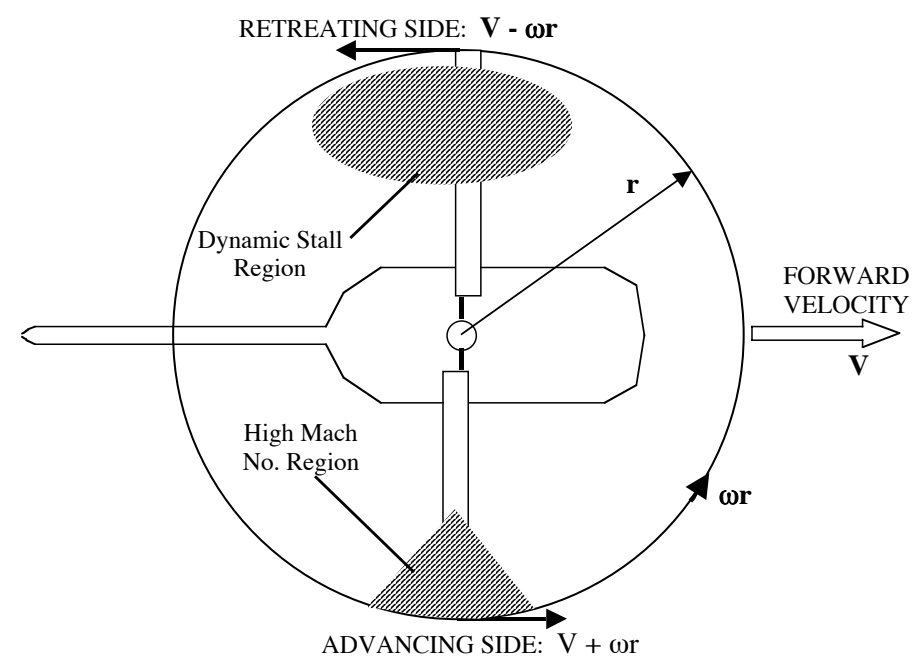

Figure 1. Flow regimes on helicopter rotor in forward flight

chord as it migrates from the leading edge and sheds at the trailing edge contributes to large lift and moment overshoots in excess of static values. As a consequence, there is significant non-linear hysteresis in the behavior of airfoil forces and moments ${ }^{1}$. Dynamic stall is the most severe type of stall that can be encountered by a retreating blade in high-speed forward flight or, indeed, maneuvering flight. The occurrence of dynamic stall on a rotor blade has adverse effects on the performance of the helicopter which include ${ }^{2}$ (a), high control system loads; (b), vibration affecting the helicopter dynamic performance in terms of speed, lift, maneuver capability and handling qualities; (c), aerodynamic performance limitations such as a loss of lift, thrust and control; and (d) stall flutter, causing blade structural damage and excessive cabin vibration. The understanding and the modification of the dynamic stall vortex that is formed under such conditions remains a major research topic in the rotorcraft industry ${ }^{3,4}$. Suppressing or eliminating the formation of the dynamic stall vortex will enhance the performance of the helicopter rotor and, hence, expand the helicopter flight envelope and vehicle utility. 
Currently, improvements to control rotor blade dynamic stall rely on conventional shape design techniques such as optimizing the blade twist distribution and plan form design. These allow the blade loading to be distributed efficiently along the rotor radius. The use of mechanical devices ${ }^{3,5}$ (such as leading- or trailing-edge flaps) and pneumatic $^{6-8}$ (such as tangential wall blowing or suction) flow control devices have shown potential improvements to rotor blade aerodynamic performance by controlling dynamic stall. Cheeseman and Seed $^{9}$, however, suggested that boundary-layer blowing provided the most attractive option because it exhibited the ability to suppress the formation of the dynamic stall vortex without either the added weight and complexities of mechanical systems or the complexity of the ducting involved with boundary-layer suction ${ }^{9}$. A disadvantage of the tangential wall blowing methods, proposed by McCloud et al. ${ }^{6}$ and Weaver et al. ${ }^{7}$, was that they required a relatively high amount of blowing $\left(\mathrm{C}_{\mu}>0.02\right)$ to be effective.

A feasibility study at City University, with funding from Westland Helicopters Ltd., successfully demonstrated the potential application of an active flow control device utilizing low energy systems to provide large improvements in performance for helicopter airfoil sections. The concept involved the use of air-jet vortex generators (AJVGs) to produce stream-wise vortices that enhanced the mixing between the retarded flow in the viscous shear layer and the high momentum fluid in the freestream ${ }^{10,11}$. As a result, the momentum deficit in the boundary layer was reduced, and so too the likelihood of boundary-layer separation. Improvements in the aerodynamic performance of a modified NACA 23012 airfoil, under quasi-steady flow conditions up to $25 \% \mathrm{C}_{\mathrm{Nmax}}$ and $6^{\circ} \alpha_{\text {stall }}$, have been demonstrated when employing low mass momentum fluxes to power the AJVG system $\left(\mathrm{C}_{\mu} \leq\right.$ $0.01)^{12}$. The need to ameliorate dynamic stall and the success of quasi-static stall control using continuous blowing AJVGs led to the idea of testing these devices on the RAE 9645 airfoil under dynamic stall conditions ${ }^{13}$. These tests demonstrated that installing a spanwise array of AJVGs at $12 \%$ chord and operating them at $\mathrm{C}_{\mu}=0.01$ successfully delayed the formation of the dynamic stall vortex.

To date, very little has been done to assess the sensitivity of the effectiveness of stall control to the blowing location. Only McCloud et al. ${ }^{6}$ have utilized more than one blowing location to study this effect and that was for pure, high-momentum, tangential blowing. They found that blowing from near the leading edge provided a successful means of controlling dynamic stall whereas blowing from the mid-chord did not. On the basis of this study alone, however, it could not have been concluded that the same would be true for an AJVG installation. 
In this paper results are presented from a series of oscillatory tests in which AJVG arrays are positioned at two locations on the upper surface of an RAE 9645 airfoil. This arrangement is used to explore the effectiveness of single array blowing and simultaneous blowing from the two locations. The influence of blowing rate for these configurations is also explored.

\section{Experimental Arrangement}

The experiments were conducted in the University of Glasgow's Handley Page low-speed closed-return wind tunnel. The test Reynolds' and Mach numbers were $1.5 \times 10^{6}$ and 0.13 respectively. The airfoil chord was $0.5 \mathrm{~m}$ with an aspect ratio of about 3. It was constructed using a fiberglass skin filled with epoxy foam and bonded to an aluminum spar. The model was mounted vertically in the octagonal working section of width $2.13 \mathrm{~m}$ and height $1.61 \mathrm{~m}$ and was pivoted about the quarter-chord position on two tubular steel shafts. These shafts were connected to the main support via two self-aligning bearings, with the weight being taken by a single thrust bearing on the top support beam. The dynamic and aerodynamic loadings from the airfoil were reacted to the wind tunnel framework by two transversely mounted beams as shown in Fig. 2. The angular movement of the model was obtained using a

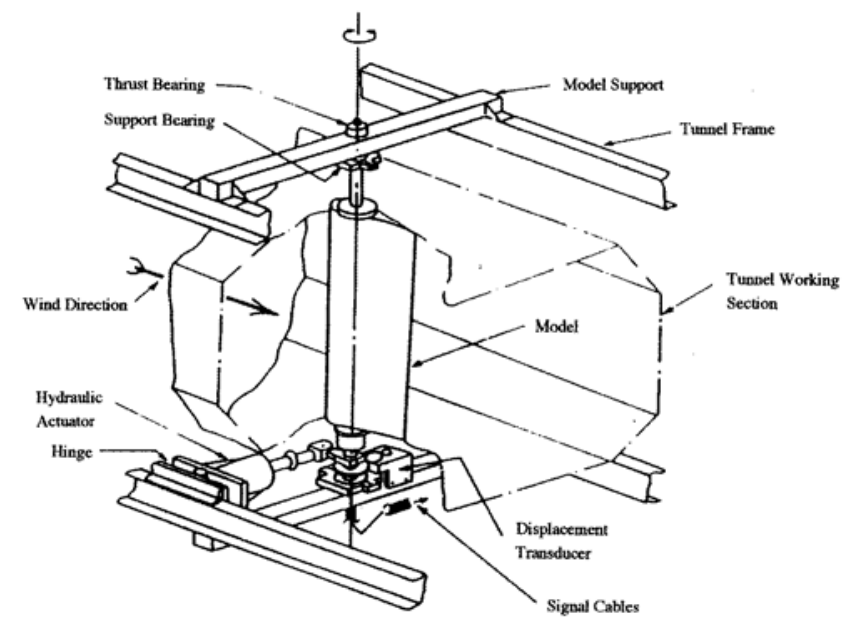

Figure 2. University of Glasgow's Dynamic Stall Rig linear hydraulic actuator and crank mechanism. The actuator was mounted horizontally below the wind tunnel working section on the supporting structure, with the crank rigidly connected to the tubular part of the spar by a welded sleeve and keyway. The actuator was a UNIDYNE 907/1 type with a normal dynamic thrust of $6.1 \mathrm{kN}$ operated from a supply pressure of 7.0Mpa. A MOOG 76 series 450 servo valve was used via a UNIDYNE servo controller unit to control the movement of the actuator. A suitable feedback signal for the controller was provided by a precision linear angular displacement transducer geared to the main spar of the model 
The model was instrumented with 30 dynamic pressure transducers, Sensor Technics SCS05GSMT, positioned along the mid-span chord-line. Output signals from the transducers were taken to a specially designed signalcontrolling unit with its own control board. On instruction from the computer, the control board automatically removed all offsets to below the A-D converter resolution and adjusted all gains as necessary. Prior to any sequence of tests, a dummy run of the most severe test, in terms of pressure range, was performed so that the amplifier gains could be automatically set to maximize the A-D resolution.

The data acquisition was carried out by a PC microcomputer interfaced with proprietary Bakker Electronics BE256 modules that provided the necessary analogue to digital conversion. The software used for data acquisition was TEAM 256. The measurement system has a capability of measuring up to 200 channels with each A-D channel having a maximum sampling rate of $50 \mathrm{kHz}$. Such a high sampling rate was required to capture the fine detail of the dynamic stall process, especially at the relatively high oscillatory frequencies tested, i.e. $0.01<\mathrm{k}<0.2$.

The motion profile for sinusoidal pitching is defined by,

$$
=15^{\circ}+10^{0} \sin \omega t
$$

where, in this case,

$$
0.3 \leq \omega \leq 5.0
$$

In all cases, tests were conducted over four continuous cycles and the data subsequently averaged.

\section{A. Design of Air-Jet Vortex Generators (AJVGs)}

The geometrical design and spacing of the AJVGs installed on the RAE 9645 were based on the recommendations outlined by Pearcey ${ }^{14}$, Henry \& Pearcey ${ }^{11}$, Akanni ${ }^{15}$ and optimized by Oliver ${ }^{16}$. The model was configured with two span-wise arrays of AJVGs in a co-rotating system, located at $\mathrm{x} / \mathrm{c}=0.12$ and 0.62 as shown in Fig. 3. The airfoil model had a total of 28 AJVGs, spaced at intervals of about $0.1 \mathrm{c}$ along the span at each of the two chordwise positions. The AJVGs had a rectangular geometric shape with a jet slot aspect ratio of about 8 and the jet exit pitched at $30^{\circ}$ and skewed at $60^{\circ}$ relative to the local surface tangent and the local free stream flow respectively 
(see Fig. 3). Air was supplied to the AJVG arrays via a pressure regulated plenum chamber located within the airfoil section. For the tests, the AJVGs were operated at low blowing momentum coefficients of between $0.0 \leq \mathrm{C}_{\mu} \leq 0.01$.

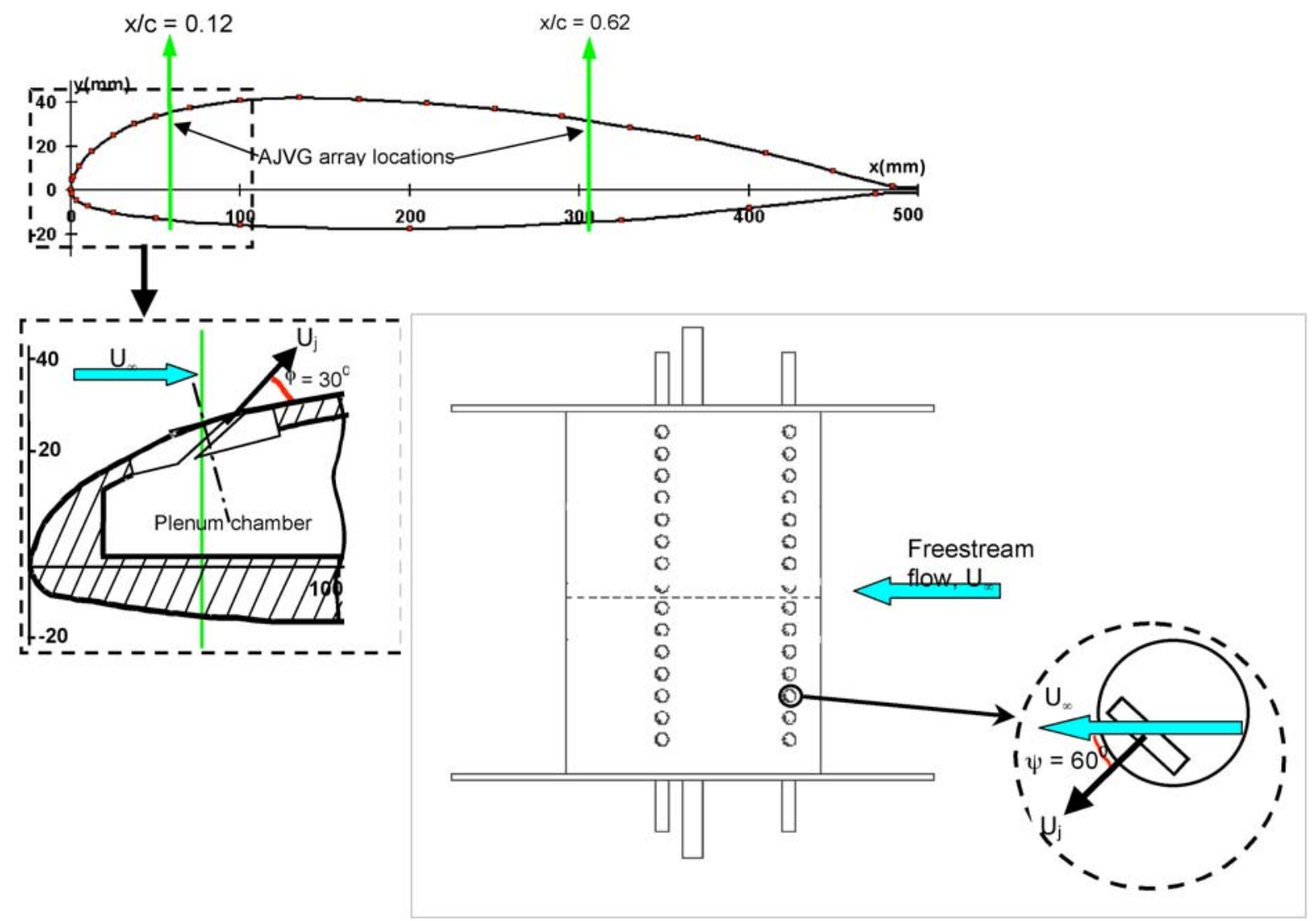

Figure 3. AJVG geometry configuration (a) pitch angle, $\phi=30^{\circ}$; and $(b)$, yaw angle $\psi=60^{\circ}$

\section{B. Measurement Accuracy}

Experimental measurement uncertainty was assessed to determine and reduce the magnitude of errors of the results obtained. Table 1 outlines some of the important parameters of the recently concluded series of tests. It should be noted that, although the normal force and pitching moment coefficient data presented here are cycle averaged, cycle to cycle variations in these coefficients do occur as a consequence of the inconsistent phasing of the 
unsteady aerodynamic events that occur during the pitch down phase. To provide an indication of the magnitude of this effect, a small number of error bars have been added to the pitch down phase of Fig. 4.

Table 1. Experimental Uncertainty

\begin{tabular}{lcc}
\hline \hline Item & Uncertainty & Operating Range \\
\hline Pressure coefficient, $\mathrm{C}_{\mathrm{P}}$ & \pm 0.1 & -12.0 to +1.0 \\
Dynamic pressure & $\pm 18 \mathrm{~Pa}$ & $1000 \mathrm{~Pa}$ \\
Blowing momentum coefficient, $\mathrm{C}_{\mu}$ & \pm 0.001 & 0.01 \\
Angle of attack, $\alpha$ & $\pm 0.1^{0}$ & $25^{0}$ \\
Model chord & $\pm 0.002 \mathrm{~m}$ & $0.5 \mathrm{~m}$ \\
\hline \hline
\end{tabular}

\section{Results And Discussion}

The effect of operating the front array of AJVGs (located at $12 \%$ chord) over a range of blowing momentum coefficients $\left(0<\mathrm{C}_{\mu} \leq 0.01\right)$ was examined for an airfoil reduced oscillation frequency of $\mathrm{k}=0.1$. This reduced frequency was chosen because it corresponds to a once per revolution variation on a typical full-scale rotor ${ }^{17,18}$. That is to say, the pitch amplitude and rotational speed of a typical helicopter rotor blade is such that the reduced

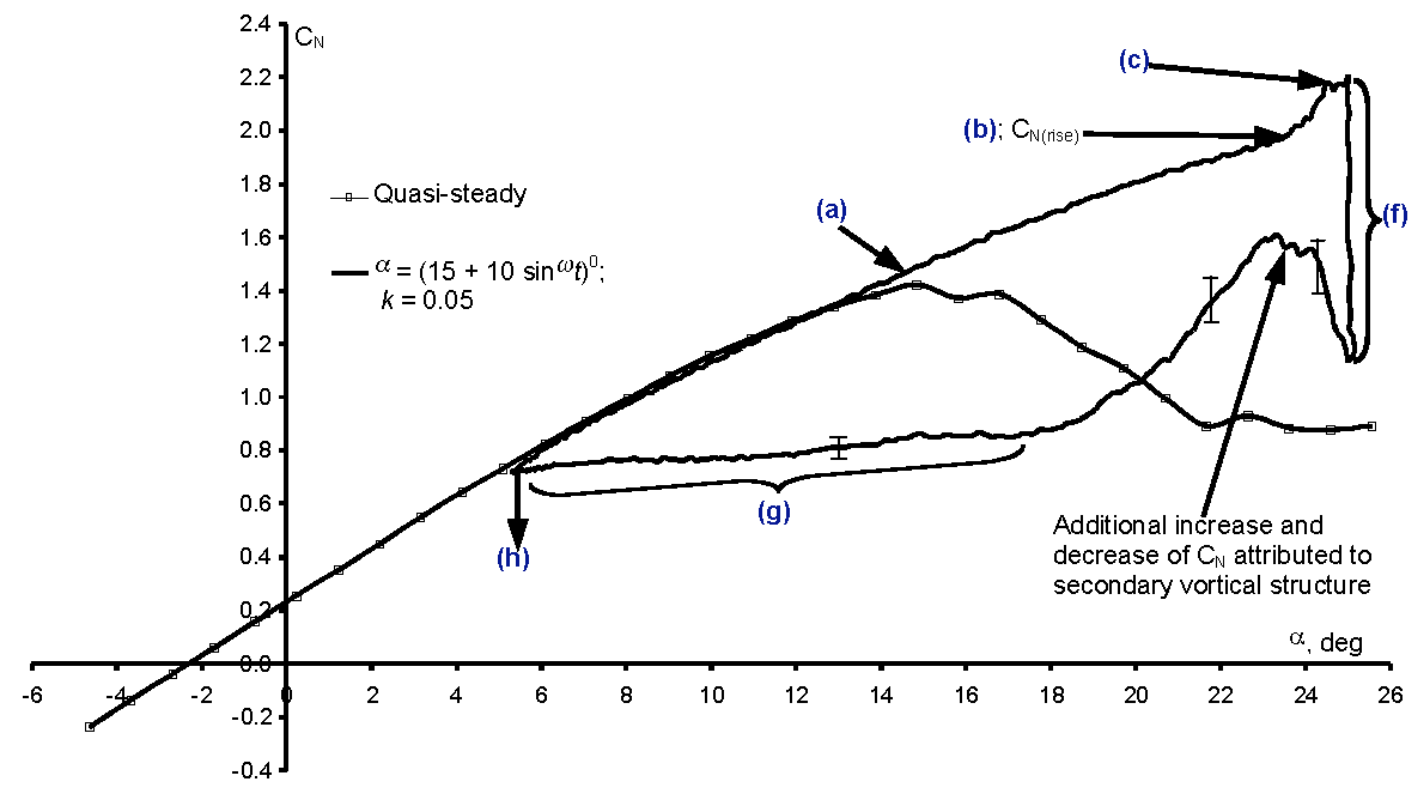

Figure 4. Normal force coefficient variation with angle of attack for unblown $R A E 9645$ at $\operatorname{Re}_{c}=1.5 \times 10^{6}$ and $M_{\infty}=0.13$ 
frequency at which the blade pitches is about 0.1 .

The integrated aerodynamic loads measured on the unblown RAE 9645 airfoil are illustrated in Figs. 4 and 5. Figure 4 shows that the airfoil significantly overshoots the quasi-steady stall angle [Fig. 4-(a)] and continues to generate additional normal force as it does so. This phenomenon is called lift overshoot. Previous experiments by Carr et al. ${ }^{19}$ showed that a pitching airfoil can tolerate large regions of reversed flow on its surface before experiencing large-scale, boundary-layer separation. This tolerance allows the airfoil to continue to increase its normal force well beyond the quasi-static stall angle.

In the present case, the normal force increases monotonically up to $\alpha \approx 23.5^{0}$ after which the slope increases nonlinearly $\left(\mathrm{C}_{\text {Nrise }}\right)$ due to the formation of the dynamic stall vortex [Fig. 4-(b)]. The stall vortex grows as the airfoil continues to pitch up, and then migrates towards the trailing edge at a speed of roughly $0.4 \mathrm{U}_{\infty}{ }^{20,21}$. When the stall vortex reaches the airfoil mid-chord the normal force achieves a maximum after which the airfoil experiences lift stall. Figure 4-(c) shows this occurs at approximately $\alpha \approx 24.5^{0}$.

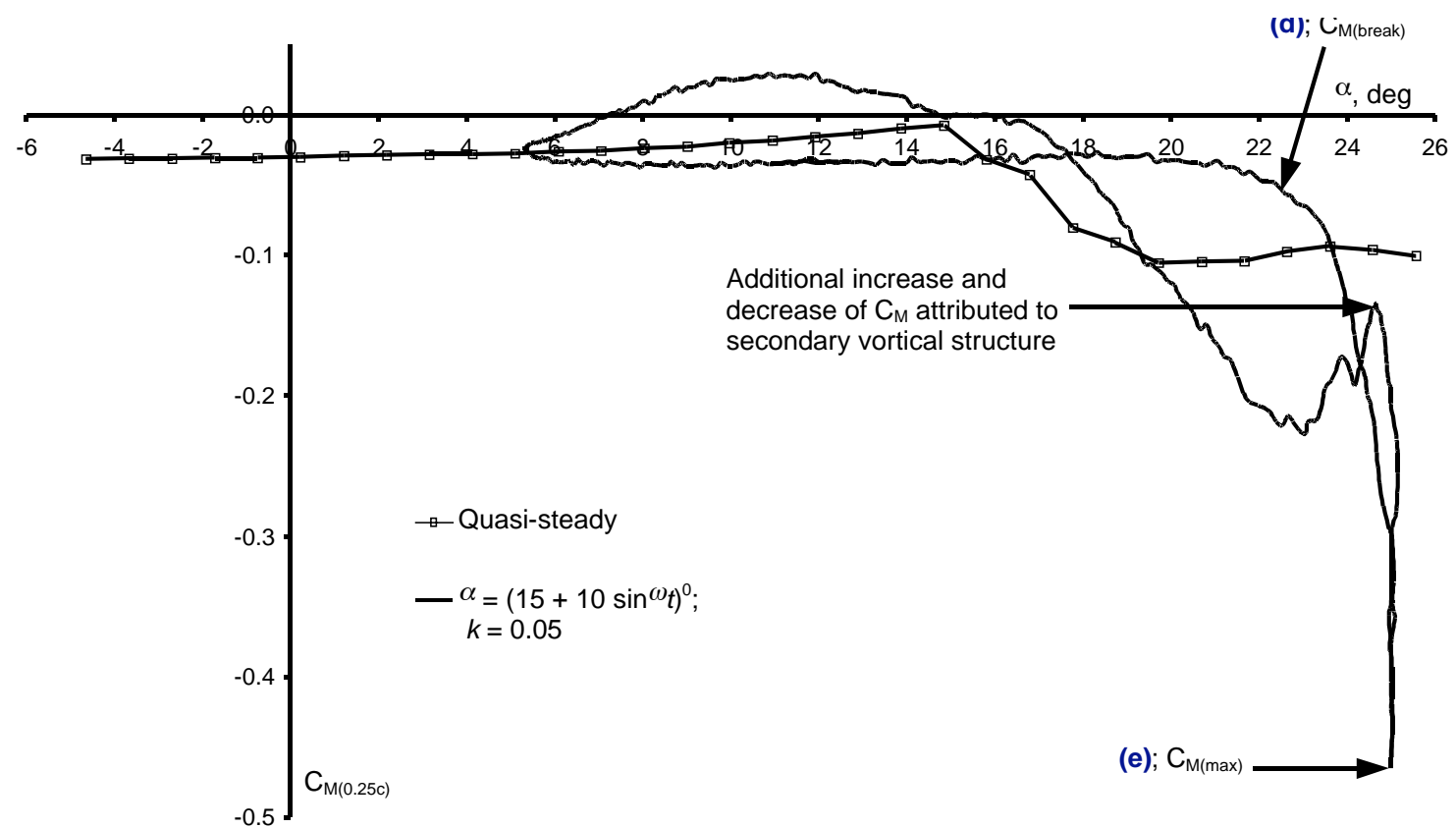

Figure 5. Quarter-chord pitching moment coefficient variation with angle of attack for unblown RAE 9645 at $\operatorname{Re}_{c}=1.5 \times 10^{6}$ and $M_{\infty}=0.13$

The rearward movement of the dynamic stall vortex, considerably alters the pressure distribution resulting in a large negative divergence of the quarter-chord pitching moment $\left(\mathrm{C}_{\text {Mbreak }}\right)$, i.e. at $\alpha \approx 20^{0}$ [Fig. 5-(d)]. This phenomenon is known as moment stall and usually occurs prior to lift stall. The negative divergence continues as the 
vortex migrates rearwards. The pitching moment curve reaches a maximum negative value $\left(\mathrm{C}_{\mathrm{Mmax}}\right)$ as the stall vortex reaches the airfoil trailing edge, i.e. at $\alpha \approx 25^{0}$ [Fig. 5-(e)].

The dynamically pitching airfoil encounters full stall when the vortex sheds from the trailing edge. The sudden and severe break in the normal force curve [Fig. 4-(f)], which in this case occurs at $\alpha \approx 25^{\circ}$, is due to the change in the direction of pitch at the top of the oscillation cycle ${ }^{19,24}$ as well as to the shedding of the dynamic stall vortex from the airfoil trailing edge. The additional or secondary increase in the normal force and break in the pitching moment can be attributed to secondary vortex shedding ${ }^{20}$.

On the down-stroke, boundary-layer reattachment is initiated at the leading edge, and moves towards the trailing edge as shown in Fig. 4-(g) ${ }^{22,23}$. The boundary-layer reattachment process is only completed towards the end of the down-stroke motion, i.e. at approximately $\alpha \approx 5^{0}$ [Fig. 4-(h)]. The significant hysteresis in the aerodynamic loads is due to the fact that the boundary layer is attached for nearly all of the upstroke motion whereas it is separated for most of the down-stroke. Boundary-layer separation persists for most of the down-stroke as the stalled wake fluid convects across the airfoil chord ${ }^{19,23}$.

Figures 6 and 7 show the effect of blowing from the front AJVG array on the aerodynamic loads of the airfoil

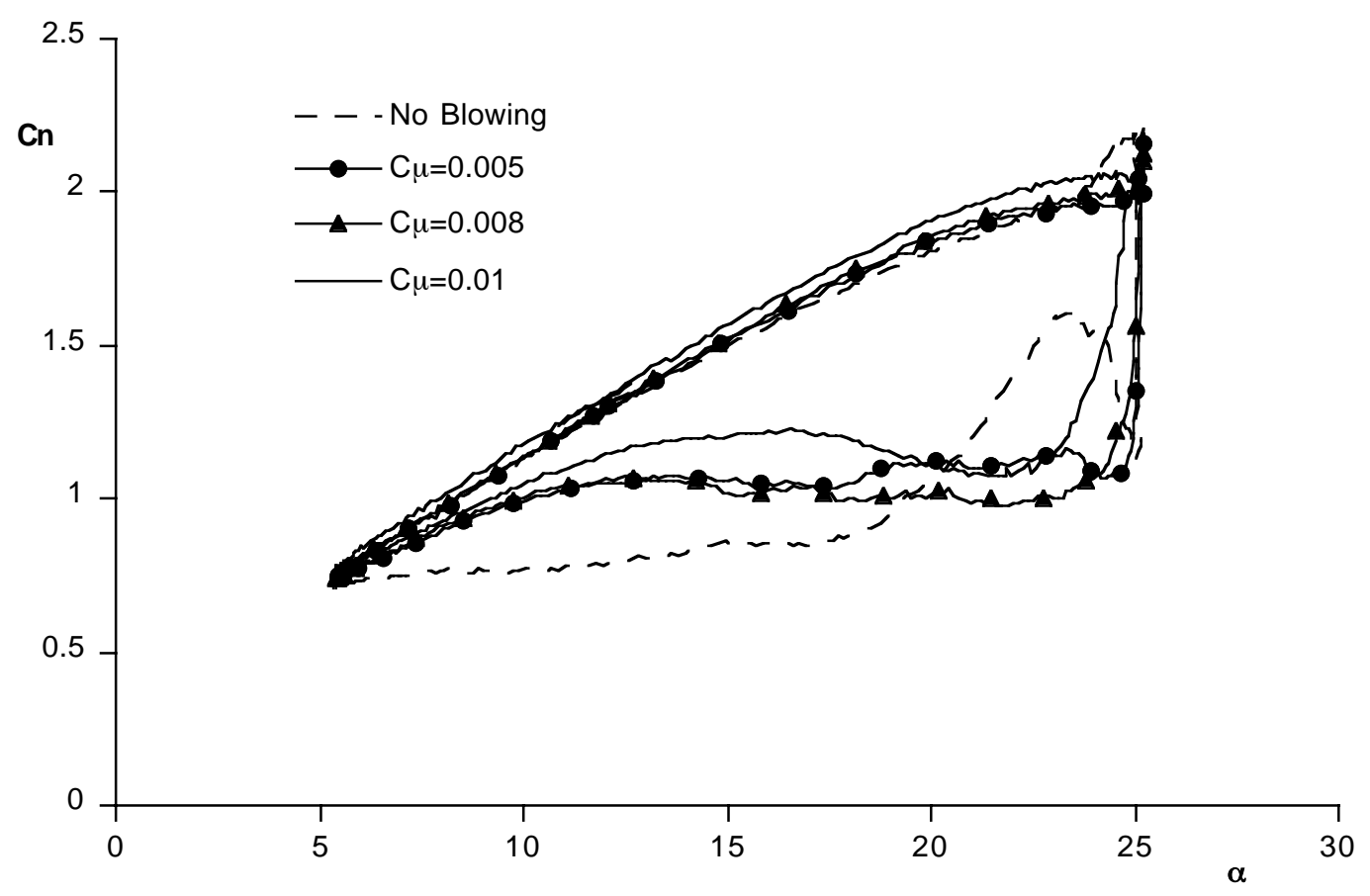

Figure 6. Normal force coefficient variation with angle of attack for RAE 9645 at $\alpha=(15+10 \sin \omega t)$ deg, $k=0.1, R_{\mathrm{c}}=1.5 \times 10^{6}$ and $\mathrm{M}_{\infty}=0.13$ with front AJVG operating 
oscillating at $\alpha=\left(15^{0}+10^{0}\right.$ sin $\left.\omega \mathrm{t}\right)$ deg at a reduced frequency, $\mathrm{k}$, of 0.1 . Carr et al. ${ }^{19}$ has shown that the initiation and forward movement of trailing-edge separation on an unblown oscillating airfoil eventually leads to the formation of a dynamic stall vortex. Therefore, the intention of blowing from the front array was to delay any such forward movement of trailing-edge separation and so control or modify the dynamic stall process ${ }^{3,7}$.

Figure 6 shows that steady blowing at $\mathrm{C}_{\mu}=0.005$ and $\mathrm{C}_{\mu}=0.008$ delays the inception of the normal force nonlinear increase $\left(\mathrm{C}_{\text {Nrise }}\right)$ by about $1^{0}$, to $\alpha \approx 24.5^{0}$. The normal force slope then increases non-linearly up to $\alpha \approx 25^{0}$ after which the normal force decreases abruptly. The observed change in the gradient of the normal force curve is attributed not only to the formation, migration and shedding of a dynamic stall vortex; but also to the change in the direction of pitch at the top of the oscillation cycle ${ }^{19,24}$. Correspondingly, the moment break and the peak nose-down moment of the quarter-chord pitching moment curve are also altered by blowing from the front AJVG array, as shown in Fig. 7. The blowing delays the pitching moment break $\left(\mathrm{C}_{\text {Mbreak }}\right)$ by about $4^{0}$, to $\alpha \approx 24^{0}$ and reduces the magnitude of the maximum negative moment $\left(\mathrm{C}_{\mathrm{Mmax}}\right)$ by about $11 \%$. It can, therefore, be suggested that blowing at $\mathrm{C}_{\mu} \leq 0.008$ influences the upstream movement of trailing-edge separation and delays the formation, migration and shedding of the dynamic stall vortex.

Also in Fig. 6. it may be observed that continuous blowing from the front array at $\mathrm{C}_{\mu}=0.01$ eliminates the nonlinear increase and abrupt decrease of the normal force gradient associated with the existence of a dynamic stall vortex. Moreover, the moment break $\left(\mathrm{C}_{\text {Mbreak }}\right)$ is delayed by about $\alpha \approx 4.5^{0}$ to the maximum angle of attack and the magnitude of the maximum negative moment $\left(\mathrm{C}_{\mathrm{Mmax}}\right)$ is reduced by about $20 \%$ (see Fig. 7). Blowing at all of the settings also has the beneficial effect of reducing the size of the clockwise hysteresis loop in the pitching moment associated with negative pitch damping.

Closer examination of the normal force curve for $\mathrm{C}_{\mu}=0.01$ reveals that, at the beginning of the pitch-down motion, the

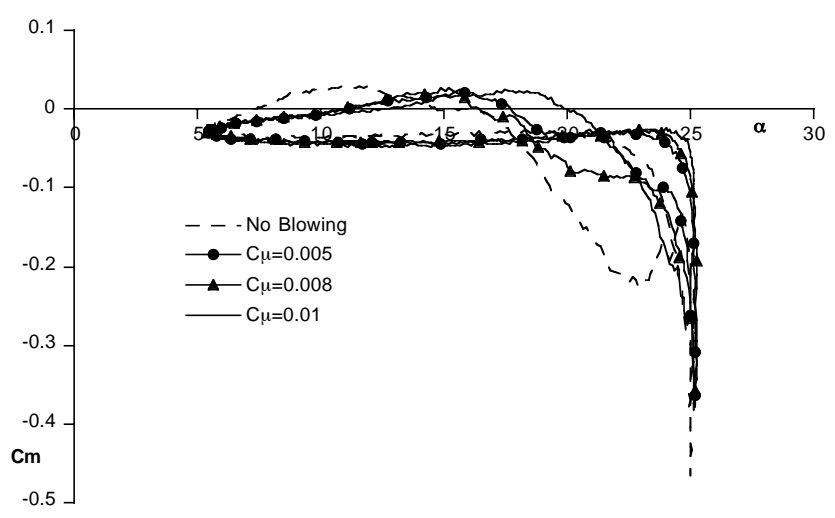

Figure 7. Quarter-chord pitching moment coefficient variation with angle of attack for RAE 9645 at $\alpha=(15+10 \sin \omega t) \operatorname{deg}, k=0.1, R_{\mathrm{c}}=$ $1.5 \times 10^{6}$ and $M_{\infty}=0.13$ with front AJVG operating 
gradient of the normal force-curve increases and then abruptly decreases indicating the possible existence of a dynamic stall vortex (see Fig. 6). With the AJVGs switched on, boundary-layer separation on the upper surface of the pitching airfoil appears to be suppressed during the pitch-up motion. As the airfoil begins to pitch down, however, the boundary layer detaches from the airfoil. It may be hypothesized that, at the beginning of the pitchdown motion, a dynamic stall vortex is shed from the airfoil contributing to the increase and decrease observed in the normal force gradient. The magnitude of the changes to the normal force suggests that this dynamic stall vortex is weak.

From the results presented, increasing the magnitude of the steady blowing progressively reduces the magnitude of hysteresis in the aerodynamic loads. Weaver et al. ${ }^{7}$ suggested that the prime cause of the hysteresis is the extent of the separation present throughout the down-stroke portion of the oscillation cycle. This suggests that blowing from the front AJVG array is effective in accelerating the process of boundary-layer re-establishment during the downstroke.

Whilst the behavior of the aerodynamic coefficients is informative, it should be remembered they are obtained by integration of the airfoil pressure distributions. These distributions, therefore, provide much more of the detail of the flow development on the airfoil. Figures 8 to 11 illustrate the temporal development of the airfoil's upper surface chordal pressure distribution in a pseudo 3-D form. For the unblown airfoil (Fig. 8) the data display all the previously discussed hallmarks of low speed dynamic stall. Initially the distribution is smooth and monotonically builds towards a peak suction at P1. Shortly before this, and not immediately obvious, there is an increase in suction

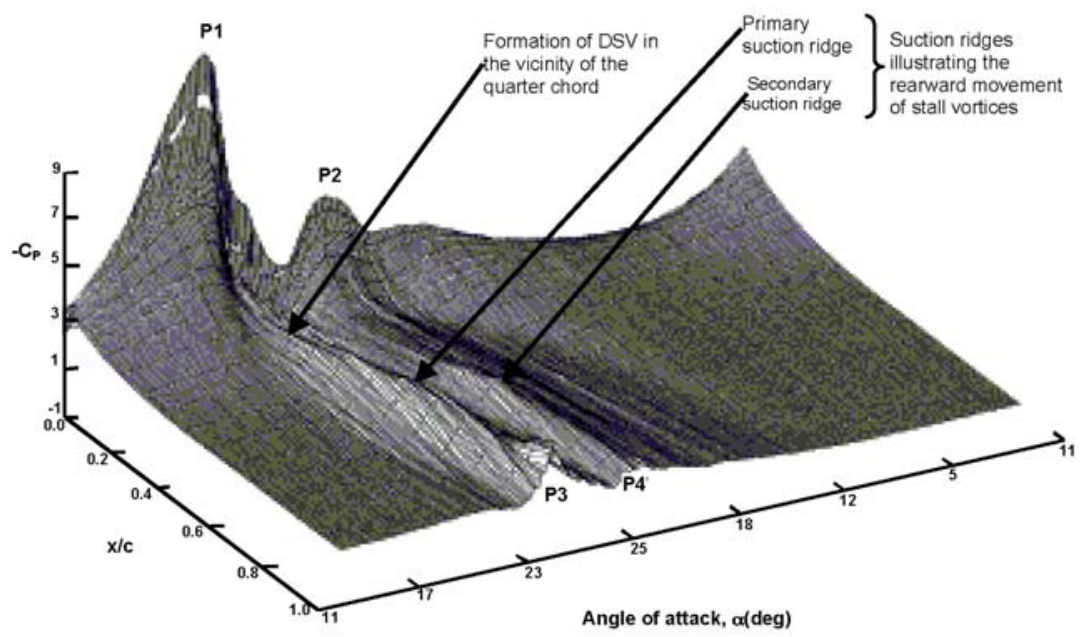

Figure 8. Instantaneous chordwise pressure distribution for unblown RAE 9645 oscillating at $\alpha=(15+10 \sin \omega t) \mathrm{deg}, k=0.1, \mathrm{Re}_{\mathrm{c}}=1.5 \times 10^{6}$ and $\mathrm{M}_{\infty}=$ 0.13 
at the trailing edge indicating the presence of some separation. Also around this time, near the $25 \%$ of chord

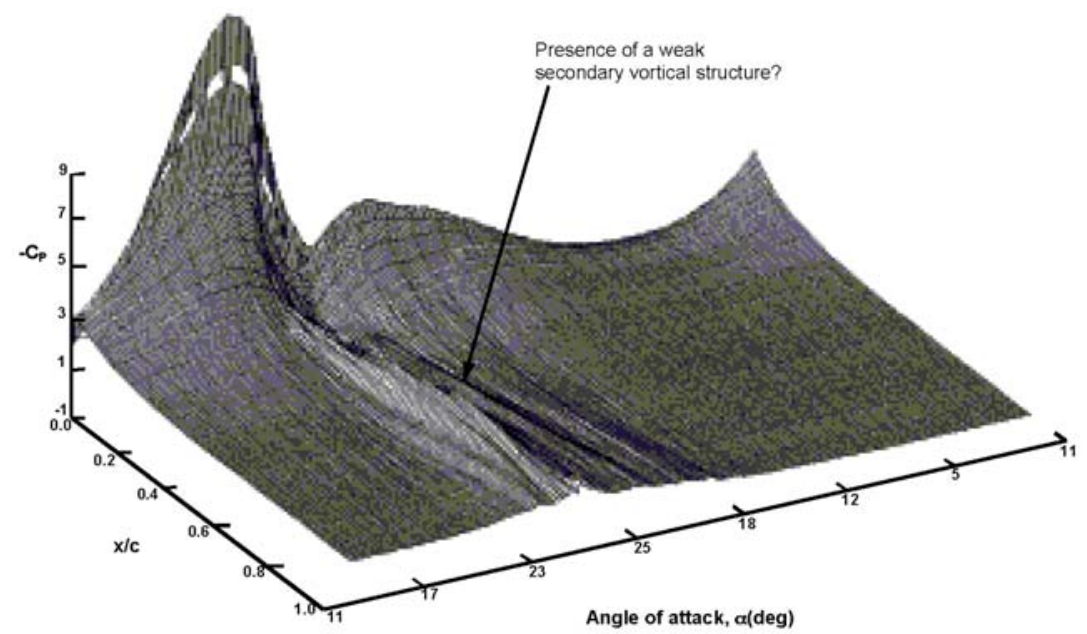

Figure 9. Instantaneous chordwise pressure distribution for RAE 9645 oscillating at $\alpha=(15+10 \sin \omega t) \mathrm{deg}, k=0.1, \operatorname{Re}_{\mathrm{c}}=1.5 \times 10^{6}$ and $\mathrm{M}_{\infty}=0.13$ with front AJVG array blowing at $\mathrm{C}_{\mu}=0.005$

location, the first indications of a deviation in the local pressure distribution herald the onset of dynamic stall ${ }^{20}$. This feature, associated with the formation of the dynamic stall vortex, develops into a well-defined ridge as the vortex grows and convects towards the trailing edge. As time advances, the leading edge suction peak collapses, and this primary ridge becomes the dominant feature of the distribution. When the vortex crosses the trailing edge, there is an obvious localized peak (P3) with an associated pressure wave that travels a short distance towards the leading edge. This is a consequence of the formation of a vortical system of opposite circulation, known as the trailing-edge vortex (TEV) and is a result of the mass influx from the high-pressure region, on the airfoil lower surface, to the upper surface ${ }^{25,26}$. As mentioned earlier, the peak nose-down moment $\left(\mathrm{C}_{\mathrm{Mmax}}\right)$ observed in Fig. 5 is attained when the dynamic stall vortex reaches the airfoil trailing edge. However, Feszty et al. ${ }^{27}$ suggested that the dynamic stall vortex only indirectly influences $\mathrm{C}_{\mathrm{Mmax}}$ by inducing the formation of the trailing-edge vortex close to the airfoil surface. The shedding of this trailing-edge vortex coincides with the maximum negative moment, $\mathrm{C}_{\mathrm{Mmax}}$.

The remainder of Fig. 8 shows the presence of a secondary suction peak, P2, in the vicinity of the leading edge, which is associated with the development of a secondary vortical structure. Likewise, the migration of the secondary vortex from the airfoil leading edge downstream towards the trailing edge is also evident. This is simply evidence of the airfoil behaving like a bluff body.

In general, the instantaneous pressure distributions for the oscillating airfoil with the front AJVG array operating (Figs. 9-11), exhibit higher leading-edge suctions than the unblown pressure distribution. This is a consequence of 
the delay in the forward movement of trailing-edge separation during the upstroke. Closer examination of Figs. 9 to 11, shows the existence of a vortex induced suction ridge associated with the passage of the stall vortex over the

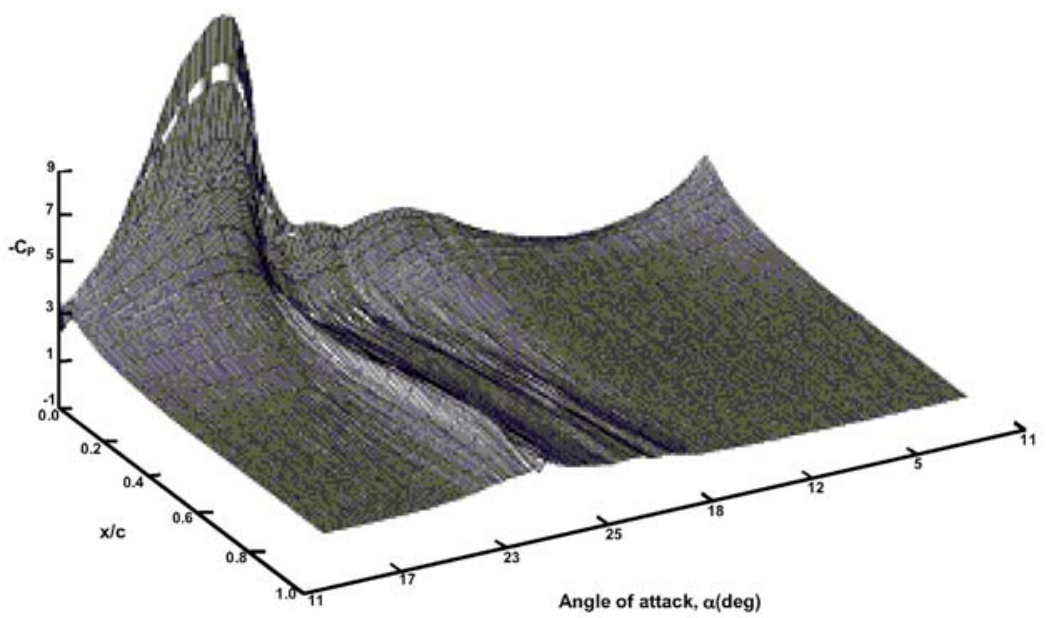

Figure 10. Instantaneous chordwise pressure distribution for RAE 9645 oscillating at $\alpha=(15+10 \sin \omega t) \mathrm{deg}, k=0.1, \operatorname{Re}_{\mathrm{c}}=1.5 \times 10^{6}$ and $\mathrm{M}_{\infty}=0.13$ with front AJVG array blowing at $\mathrm{C}_{\mu}=0.008$

upper surface of the airfoil. This observation is consistent with the presence of vortex lift in the aerodynamic loads as shown in Figs. 6 and 7. The reduction of the suction ridge height suggests that the strength of the dynamic stall vortex is progressively reduced when the amount of steady AJVG blowing is increased from $\mathrm{C}_{\mu}=0.005$ to $\mathrm{C}_{\mu}=$ 0.01. It may, therefore, be postulated that the formation of the dynamic stall vortex has been modified beneficially in all cases and almost eliminated when $\mathrm{C}_{\mu}>0.008$.

As mentioned above, and shown in Fig. 3., two AJVG arrays were installed on the upper surface of the airfoil

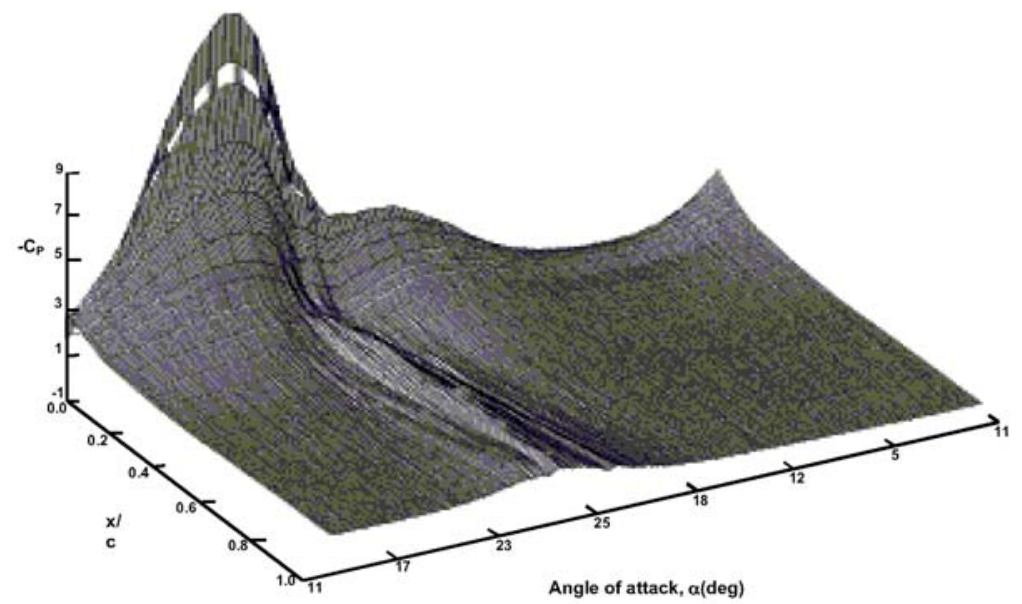

Figure 11. Instantaneous chordwise pressure distribution for RAE 9645 oscillating at $\alpha=(15+10 \sin \omega t) \operatorname{deg}, k=0.1, \mathrm{Re}_{\mathrm{c}}=1.5 \times 10^{6}$ and $\mathrm{M}_{\infty}=0.13$ with front AJVG array blowing at $C_{\mu}=0.01$ 
model; one at $\mathrm{x} / \mathrm{c}=0.12$ and the other at $\mathrm{x} / \mathrm{c}=0.62$. Upon establishing that blowing at $\mathrm{C}_{\mu}=0.01$ from the $\mathrm{x} / \mathrm{c}=0.12$ location significantly modified the airfoil performance, subsequent tests were carried out to examine the effect of blowing from the rearward array and from a combination of the two arrays. In all of these tests, the blowing coefficient was held constant at $\mathrm{C}_{\mu}=0.01$. Figures 12 and 13 present the results of these tests and compare them with the corresponding front array results and those of the unblown case.

In Fig. 12 it may be seen that with only the rear array operational, the normal force and pitching moment responses are quite different to both the results obtained for the front array and unblown cases. The build up of normal force on the upstroke closely follows the front blowing case suggesting that the rear array is effective at suppressing trailing edge separation. The manner of stall is, however, significantly different. Close inspection reveals the classical characteristics of $\mathrm{C}_{\mathrm{N}}$ rise due to dynamic stall vortex build up before the top of the cycle. This occurs slightly later than the unblown case but is in stark contrast to the front array blowing case where the only evidence of possible dynamic stall vortex formation occurs near the start of the downstroke. Similarly, although the corresponding pitching moment break is delayed in comparison to the unblown case (Fig. 13), the magnitude of the delay is considerably less than that achieved by blowing from the front array. More significantly, the magnitude of

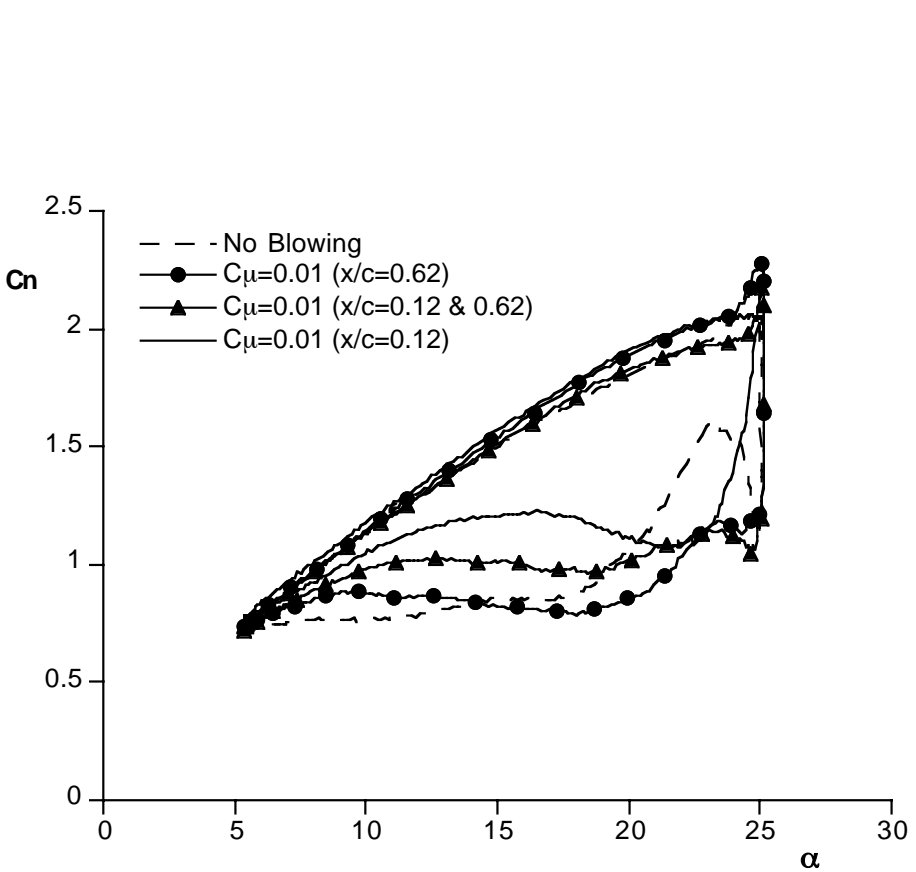

Figure 12. Normal force coefficient variation with angle of attack for RAE 9645 at $\alpha=(15+10 \sin \omega t) \operatorname{deg}, k=0.1, \operatorname{Re}_{\mathrm{c}}=1.5 \times 10^{6}$ and $\mathrm{M}_{\infty}=0.13$ with $\mathrm{C} .=\mathbf{0 . 0 1}$ the break is almost twice that of the front array blowing case.

When the two AJVG arrays are operated at the same time, there is only a marginal improvement over the rear blowing case. Nevertheless, the normal force and pitching moment responses for this case are interesting and provide more insight into the way in which the AJVGs alter the flow. On the upstroke, the combined blowing produces a normal force curve that closely follows the unblown case. It should be borne in mind 
that by operating the dual array configuration at the same overall blowing momentum coefficient as a single array, the momentum efflux from each array is half that used for the single array blowing. The fact that the normal force curve for the combined blowing case is similar to the unblown case suggests that the momentum efflux from the jets is not strong enough to energize the boundary layer sufficiently at either of the two array locations to delay trailing edge separation. This implies that the AJVG injection velocity is a critical parameter in determining the boundary layer response.

As in the previous case, dynamic stall onset is clearly visible in the combined blowing case. Interestingly, the incidence at which this occurs is slightly higher than the rear blowing case, suggesting that the front array is partially effective in delaying stall onset. In this respect, it is interesting to compare this result with the front blowing case of $\mathrm{C}_{\mu}=0.005$ (Fig. 14).

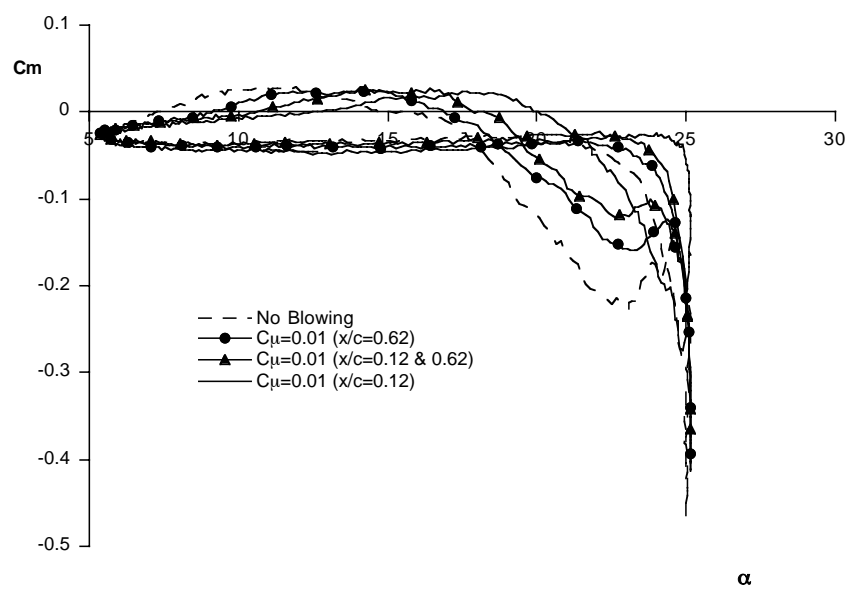

Figure 13. Quarter-chord pitching moment coefficient variation with angle of attack for RAE 9645 at $\alpha=(15+10 \sin \omega t) \operatorname{deg}, k=0.1, \operatorname{Re}_{\mathrm{c}}=$ $1.5 \times 10^{6}$ and $M_{\infty}=0.13$ with $C_{u}=0.01$

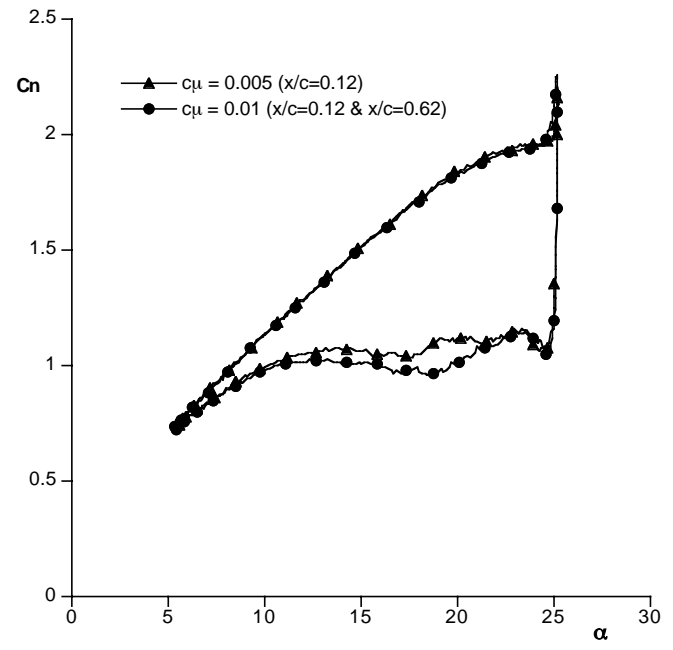

Figure 14a. Normal force coefficient comparison of combined and front only blowing cases $\alpha=(15$ $+10 \sin \omega t) \operatorname{deg}, k=0.1, \operatorname{Re}_{c}=1.5 \times 10^{6}$ and $M_{\infty}=$ 0.13

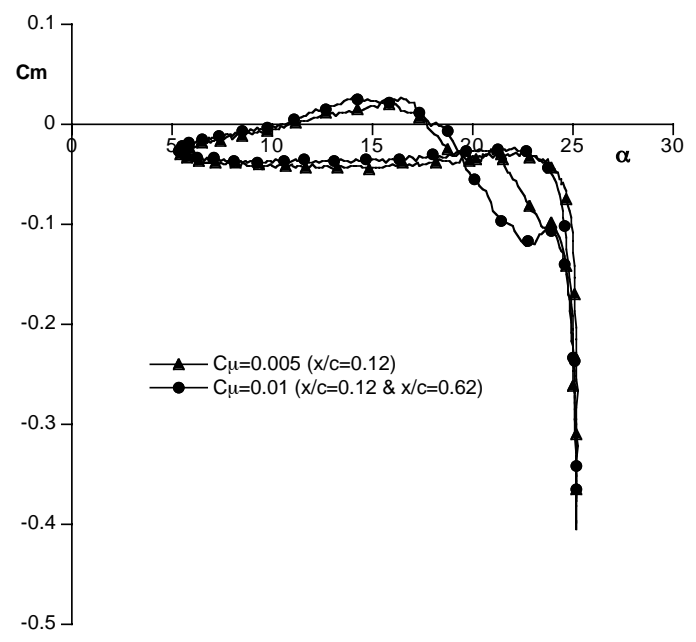

Figure 14b. Pitching moment coefficient comparison of combined and front only blowing cases $\alpha=(15+10 \sin \omega t) \mathrm{deg}, k=0.1, \operatorname{Re}_{\mathrm{c}}=1.5 \times 10^{6}$ and $M_{\infty}=\mathbf{0 . 1 3}$ 
There is remarkable similarity between the two cases during the pitch up phase implying that the front array is the dominant flow control device there. The front array alone also produces a slight reduction in the negative pitch damping, associated with changes to the pitching moment during the pitch down phase.

Overall, when compared to the unblown case, AJVGs improve the low speed dynamic stall characteristics of the RAE9645 airfoil. The placement and strength of the active AJVGs is, however, important as has been amply demonstrated in this study. Whilst these experiments have been concerned with pitching oscillations that represent helicopter blade motions, the interpretation of the data has been complicated by the angular acceleration of the airfoil. This is particularly the case at the top of the pitch cycle where much of the dynamic content of the response occurs within a relatively small incidence range. The evolution of the stall and the re-establishment of fully attached flow after stall can be better examined using linear ramp motions, ramp-up and ramp-down, that consider the two effects independently ${ }^{28}$. Data from such tests are currently under analysis.

\section{Conclusion}

Tests conducted on a single-element airfoil oscillating in pitch according to the profile $\alpha=\left(15^{0}+10^{0} \sin \omega \mathrm{t}\right)$, for the reduced oscillation frequency of $k=0.1$ and incorporating two spanwise arrays of AJVGs have shown that:

1) Blowing from the front AJVG array considerably enhanced the overall aerodynamic performance of the oscillating RAE 9645 airfoil compared with blowing from either the rear AJVG array or from both the front and rear AJVG arrays simultaneously (with the same total mass flux).

2) Blowing from the front AJVG array at $C_{\mu}=0.01$ apparently weakens the dynamic stall vortex to the extent that its effect on the normal force and pitching moment responses is minimal.

The present work is restricted to low-speed dynamic stall. Above a threshold of Mach 0.3, the effect of compressibility is pronounced and accelerates the initiation of the dynamic stall vortex and changes the mechanism of dynamic stall onset from that observed in low-speed experiments ${ }^{29,30}$. Moreover, on most modern helicopters the retreating blade works at a Mach number of about $0.4^{31}$. Although the effectiveness of AJVGs in compressible flow and, in particular, for controlling shock induced separation has been demonstrated ${ }^{14}$, the blowing requirements may increase under these conditions. The optimum jet location on the blade may also change, particularly if shock 
induced separation occurs upstream of the current jet location. The sensitivity of the AJVG effectiveness to real rotor effects such as flow skew angle, radial flow and time varying Mach number may also be an issue. In addition, if used continuously around the azimuth, the influence of the AJVGs on the advancing side of the rotor also needs to be investigated.

Nevertheless, the potential application of low-momentum blowing AJVGs to assuage dynamic stall and enhance airfoil performance characteristics has been demonstrated in the current work. If this can be replicated on the highlift producing radial blade locations on a helicopter rotor it could have a significant impact on future rotor performance.

\section{Acknowledgments}

The work was carried out with funding from the Engineering \& Physical Science Research Council, (Grant Ref GR/M85432/01), Westland Helicopters and DSTL (formerly DERA). The authors acknowledge with gratitude the help and support of their sponsors and, in particular, the substantial contributions of Mr Robert Gilmour, Mr Christopher Barber and Mr Michael Smith to this work.

\section{References}

${ }^{1}$ Johnson, W., Helicopter Theory, Princeton University Press, 1980.

${ }^{2}$ Bousman, W. G., "A Qualitative Examination of Dynamic Stall from Flight Test Data”, AHS 53rd Annual Forum Proceedings, 1997, pp. 368-387.

${ }^{3}$ Yu, Y. H., Lee, S., McAllister, K. W., Tung, C., and Wang, C. M., "Dynamic Stall Control for Advanced Rotorcraft Application”, AIAA Journal, Vol. 33, No. 2, 1995, pp. 289-295.

${ }^{4}$ Teves, D., Nisel, G., Blaas, A., and Jacklin, S., "The Role of Active Control in Future Rotorcraft", 21st European Rotorcraft Forum, Paper III-10, 1995. 
${ }^{5}$ Chan, W. and Brocklehurst, A., "Performance enhancement evaluation of an actuated trailing edge flap", The Aeronautical Journal, Vol. 105, No. 1049, July 2001, pp. 391-399.

${ }^{6}$ McCloud III, J.L., Hall, L.P., and Brady, J.A., "Full-Scale Wind-Tunnel Tests of Blowing Boundary-Layer Control Applied to a Helicopter Rotor", NASA Technical Note D-335, 1960.

${ }^{7}$ Weaver, D., McAllister, K. W., and Tso, J., "Suppression of Dynamic Stall by Steady and Pulsed Upper-Surface Blowing”, NASA Technical Paper 3600, 1996.

${ }^{8}$ Alferai, M., and Acharya, M., "Controlled leading-edge suction for the management of unsteady separation over pitching aerofoils", AIAA paper 95-2188, 26th AIAA Fluid Dynamics Conference, 1995.

${ }^{9}$ Cheeseman, I. C. and Seed, A.R., "The Application of Circulation Control by Blowing to Helicopter Rotors", Journal of The Royal Aeronautical Society, Vol. 71, No. 679, July 1967, pp. 451-467.

${ }^{10}$. Johnston, J. P., and Nishi, M., “ Vortex Generator Jets - Means for Flow Separation Control”, AIAA Journal, Vol. 28, No. 6, 1990, pp. 989-994.

${ }^{11}$ Henry, F. S., and Pearcey, H. H., "Numerical Model of Boundary-Layer Control Using Air-Jet Generated Vortices", AIAA Journal, Vol. 32, No. 12, 1994, pp. 2415-2424.

${ }^{12}$ Lewington, N. P., Peake, D. J., Henry, F. S., Kokkalis, A., and Perry, J., “The Control of Flow on Helicopter Rotor Blades”, Proc. of 26th European Rotorcraft Forum, The Hague, Netherlands. September 2000.

${ }^{13}$ Singh, C., Peake, D. J., Kokkalis, A., Coton, F., and Galbraith, R., "Control of flow on helicopter rotor blades under quasisteady and unsteady flow conditions using smart air-jet vortex generators", Proc of 29th European Rotorcraft Forum, Germany, 16-18 September 2003.

${ }^{14}$ Pearcey, H. H., Shock induced separation and its prevention by design and boundary layer control, Pergamon Press, pp. 1166-1134, 1961.

${ }^{15}$ Akanni, S. D., and Henry, F. S., "Numerical calculations of air-jet vortex generators in turbulent boundary layers", $C E A S$ European Forum on 'High Lift \& Separation Control', Paper 16, 1995.

${ }^{16}$ Oliver, A. G., “Air jet vortex generators for wind turbines”, PhD Thesis, City University (London), Centre for Aeronautics, 1997.

${ }^{17}$ Wilby, P. G., "The aerodynamic characteristics of some new RAE blade sections, and their potential influence on rotor performance", Vertica, Vol. 4, 1980, pp. 121-133.

${ }^{18}$ Wilby, P. G., "An experimental investigation of the influence of a range of aerofoil design features on dynamic stall onset", 10th European Rotorcraft Forum, Paper No 2, 1984. 
${ }^{19}$ Carr, L. W., McAllister, K. W., and McCroskey, W. J., “Analysis of the development of dynamic stall based on oscillating airfoil experiments”, NASA Technical Note D-8382, 1977.

${ }^{20}$ McCroskey, W. J., “The phenomenon of dynamic stall”, NASA Technical Memorandum 81264, 1981.

${ }^{21}$ Green, R. B., Galbraith, R. A. McD., and Niven, A. J., "Measurements of the Dynamic Stall Vortex Convection Speed", The Aeronautical Journal, Vol. 96, No. 958, 1992, pp. 319-325.

${ }^{22}$ Ahmed, S., and Chandrasekhara, M. S., "Reattachment Studies of an Oscillating Aerofoil Dynamic Stall Flowfield", AIAA Journal, Vol. 32, No. 5, 1994, pp. 1006-1012.

${ }^{23}$ Green, R. B., and Galbraith, R. A. McD., "Dynamic recovery to fully attached aerofoil flow from deep stall”, AIAA Journal, Vol. 33, No. 8, 1995, pp. 1433-1440.

${ }^{24}$ McAllister, K. W., and Carr, L. W., "Water Tunnel Visualisations of Dynamic Stall”, Journal of Fluids Engineering, Vol. 101, September 1979, pp. 376-380.

${ }^{25}$ Robinson, M. C., Helin, H. E., and Luttges, M. W., "Control of Wake Structure Behind an Oscillating Aerofoil”, AIAA Paper 86-2282.

${ }^{26}$ Shih, C., Lourenco, L., Van Dommelen, L., and Krothapalli, A., "Unsteady Flow Past an Aerofoil Pitching at a Constant Rate”, AIAA Journal, Vol 30, No 5, 1992, pp 1153-1161.

${ }^{27}$ Feszty, D., Gillies, E.A., and Vezza, M., “Alleviation of Rotor Blade Dynamic Stall via Trailing Edge Flap Flow Control”, AIAA Paper 2003-0020, 41st Aerospace Sciences Meeting and Exhibit, Jan 2003.

${ }^{28}$ Coton, F. N., and Galbraith, R. A. McD., "An experimental study of dynamic stall on a finite wing”, The Aeronautical Journal, Vol. 103, No. 1015, May 1999, pp. 229-236.

${ }^{29}$ Chandrasekhara, M. S., and Carr, L. W., “ Flow Visualisation Studies of the Mach Number Effects on Dynamic Stall of an Oscillating Aerofoil”, Journal of Aircraft, Vol. 27, No. 6, 1990, pp. 516-522.

${ }^{30}$. Chandrasekhara, M. S., and Carr, L. W., "Compressibility Effects on Dynamic Stall of Oscillating Aerofoils”, AGARD CP-552, Paper 3, 1995.

${ }^{31}$ St. Hilaire, A. O., Carta, F. O., Fink, M. R., and Jepson, W. D., “The Influence of Sweep on the Aerodynamic Loading of an Oscillating NACA 0012 Aerofoil”, Vol 1 - Technical Report, NASA CR 3092, 1979. 